\title{
PENGARUH MEDIA LEAFLET DAN FILM TERHADAP PENGETAHUAN TENTANG KANKER SERVIKS DAN PARTISIPASI WANITA DALAM DETEKSI DINI KANKER SERVIKS DI KAMPUNG DAREK KECAMATAN PADANGSIDEMPUAN SELATAN TAHUN 2015
}

\author{
Ayu Ulfah Nur Lubis ${ }^{1}$, Erna Mutiara ${ }^{2}$, Taufik Ashar ${ }^{2}$ \\ ${ }^{1}$ Alumni Pascasarjana Ilmu Kesehatan Masyarakat USU-Medan \\ ${ }^{1}$ Staf Pengajar Fakultas Kesehatan Masyarakat USU-Medan
}

\begin{abstract}
Cervical cancer is a health problem which spreads among the countries throughout the world including Indonesia. It has the highest rank in diseases suffered by women in the developing countries. The data from Indonesian Cancer Foundation (2013) revealed that around 500,000 women were diagnosed as being suffered from cervical cancer each year and more than 250,000 of them died. The objective of the research was to find out the influence of the media of leaflets and movie on the knowledge of cervical cancer and women's participation in early detection of cervical cancer. The research used quasi experiment design with non-equivalent control group. The population was 116 women 18 years old above, had been married, and lived at Darek Village, Padangsidempuan Selatan Subdistrict, Padangsidempuan City. The samples consisted of three groups with 30 respondents in each group, taken by using purposive sampling technique. The analyzed by using paired t-test, Wilcoxon, One Way Anova and Kruskal Wallis test. The result of the research showed that there was the difference in the change of knowledge about cervical cancer after health education had been given using the media of leaflets and films $(p=0.028)$. It is suggested that the health office in Padangsidempuan Selatan subdistrict to give health education about early detection program of cervical cancer by using leaflets and movie media that is more interesting so the community interest in increasing their knowledge and participation in detecting cervical cancer.
\end{abstract}

Keywords : Leaflet, Film, Knowledge, Participation, Cervical Cancer

\section{PENDAHULUAN}

Menurut badan kesehatan dunia (WHO) dari 2009 sampai 2013 menurut data kasus penderita kanker serviks meningkat dari 1,4 juta menjadi 12,7 juta. WHO juga menyatakan selalu ada kasus baru terkait kanker, sampai saat ini sudah 28 jenis kanker ada di 184 negara diseluruh dunia. Selama lima tahun itu jumlah kematian yang disebabkan kanker melonjak dari 7.600.000 menjadi 8.200.000 dan lebih dari setengahnya berasal dari negara berkembang.

Data yang di peroleh dari dinas kesehatan Provinsi Sumatera Utara jumlah penderita kanker serviks di Sumatera Utara pada tahun 2010 terdapat 475 kasus, tahun 2011 terdapat 548 kasus dan tahun 2012 terdapat 681 kasus. Di rumah sakit pemerintah di RSUD Dr. Pringadi medan pada tahun 2011 terdapat 51 kasus, tahun 2012 terdapat 58 kasus, tahun 2013 terdapat 67 kasus dan tahun 2014 terdapat 84 kasus. Di RSUP H. Adam Malik Medan pada tahun 2011 terdapat 148 kasus, tahun 2012 terdapat 300 kasus, tahun 2013 terdapat 328 kasus, dan tahun 2014 terdapat 335 kasus. Data yang diperoleh dari RSU Kota Padangsidempuan jumlah penderita kanker serviks pada tahun 2013 terdapat 31 kasus dan meningkat tahun 2014 sebanyak 38 kasus dimana kebanyakan pasien kanker serviks sudah stadium lanjut di Rujuk Ke RSU. H. Adam Malik Medan untuk melanjutkan pengobatan dan mendapatkan fasilitas yang lebih baik.

Upaya penanggulangan penyakit kanker serviks telah dilakukan yaitu dengan melakukan program skrining kanker seviks, namun hasil-hasil penelitian di beberapa negara masih menunjukkan kurangnya partisipasi wanita untuk mengikuti program skrining (Rachmadahniar, 2005). Penelitian yang dilakukan Dewi, dkk (2013), di Puskesmas Buleleng, Surabaya 21 wanita $(30 \%)$ dari 70 wanita yang mau melakukan deteksi dini kanker serviks, disebabkan kurangnya kesadaran wanita yang sudah menikah atau sudah pernah melakukan hubungan seksual untuk melakukan deteksi dini (Pap Smear atau Test IVA). Ada hal lain yang mempengaruhi wanita untuk mendeteksi dini kanker serviks yaitu kurangnya informasi mengenai pentingnya pemeriksaan Pap Smear atau IVA. Sebagian besar penderita kanker datang sudah dalam stadium lanjut sehingga prosesnya sulit atau tak mungkin lagi di sembuhkan. Hal ini menunjukkan bahwa pengetahuan masyarakat tentang kanker serviks 
masih tergolong rendah, sehingga kesadaran masyarakat untuk skrining kanker serviks juga rendah (Tyastuti, 2008).

Pencegahan dan pengobatan prakanker serviks masih merupakan masalah kesehatan masyarakat di antara wanita dewasa di Indonesia. Masih tingginya angka penderita kanker serviks di Indonesia di sebabkan oleh rendahnya kesadaran wanita untuk memeriksa kesehatan dirinya. Padahal kini, penyakit apapun sudah dapat diobati dan ditangani secara cepat, dengan pendeteksian dini yang dilakukan secara berkala sehingga dapat mengurangi risiko angka kematian (Setiati, 2009). Keterlambatan penderita datang berobat untuk itu perlunya upaya penanganan dan pengobatan prakanker serviks yang menjadi prioritas. Setiap wanita yang telah melakukan hubungan seksual mempunyai risiko menderita kanker serviks. Pemeriksaan ini bukan sekali seumur hidup, melainkan dilakukan rutin tiap tahun sampai usia 70 tahun (Ocvyanti, 2013).

Cara deteksi dini yang paling sering dilakukan ialah metode usapan lendir (pap smear) leher rahim menurut Papanicolaou atau sering dikenal dengan pap smear. Petugas kesehatan akan melakukan pengambilan lendir pada leher rahim dengan cara usapan (pap smear) untuk kemudian diperiksa di laboratorium. Selain pemeriksaan pap smear ada cara lain yang lebih sederhana yaitu dengan cara Inspeksi Visual setelah meneteskan asam cuka atau asam asetat 3\%-5\%, yang dinamakan dengan IVA (inspeksi visual dengan asam asetat) atau IVA (visual inspection with acitic acid). Metode ini sangat menguntungkan karena biaya untuk pemeriksaan cukup terjangkau (Prawirohardjo, 2006).

Berdasarkan data di Laboratorium Prodia Kecamatan Padangsidempuan Selatan Kota Padangsidempuan wanita yang melakukan pap smear tahun 2013 sebanyak 21 orang, tahun 2014 sebanyak 38 orang, dan sampai akhir bulan Februari 2015 sebanyak 18 orang. Berdasarkan survei pendahuluan melalui wawancara yang dilakukan bulan Februari 2015 dengan 10 orang wanita di Lingkungan Kampung Darek Kecamatan Padangsidempuan Selatan Kota Padangsidempuan bahwa sebanyak 6 orang $(60 \%)$ tidak mengetahui program deteksi dini kanker serviks seperti pap smear dan kurangnya pengetahuan wanita terhadap deteksi dini kanker serviks, 2 orang $(20 \%)$ mengetahui tentang program deteksi dini kanker serviks seperti pap smear serta terdapat 2 orang (20\%) wanita yang menderita kanker serviks di Lingkungan Kampung Darek.

Berdasarkan informasi dari Dinas Kesehatan Kota Padangsidempuan bahwa selama ini penyuluhan tentang kanker serviks dilakukan dengan metode ceramah dan poster tetapi dirasakan masih kurang efektif untuk meningkatkan pengetahuan dan partisipasi wanita. Pada metode ceramah penyuluhan lebih banyak memegang peran untuk menyampaikan dan menjelaskan materi penyuluhannya sehingga hanya dimengerti pada saat ceramah dilakukan dan mengingat poster sesaat. Maka dengan mencoba memberikan media leaflet dan video memiliki pengaruh yang besar terhadap peningkatan pengetahuan dan partisipasi wanita yang dapat menyimpan leaflet dan mudah mengingatnya melalui pemutaran video tentang kanker serviks.

\section{METODE}

Jenis penelitian ini adalah Quasi Experiment Design. Kelompok yang diintervensi terdiri atas 2 (dua) subjek penelitian yang diberikan perlakuan berbeda. Kelompok 1 diberi perlakuan dengan media Leaflet dan pada kelompok 2 diberi perlakuan film.

Populasi dalam penelitian ini adalah seluruh wanita yang berusia di atas 18 tahun, sudah menikah dan tinggal menetap di Lingkungan Kampung Darek Kecamatan Padangsidempuan Selatan Kota Padangsidempuan, sebanyak 116 orang.

Besar sampel yang digunakan dalam penelitian ini berjumlah 3 kelompok perwiritan dengan masingmasing 30 responden. Teknik pengambilan sampel dalam penelitian ini adalah purposive sampling yaitu pengambilan sampel secara bertujuan. Besar sampel dipilih mengikuti prosedur tertentu sehingga dapat mewakili populasinya.

\section{HASIL}

\section{Pengaruh Pendidikan Kesehatan dengan Metode Leaflet dan Film Terhadap Pengetahuan tentang Kanker Serviks}

Hasil penelitian diketahui terjadi perubahan nilai rata-rata pengetahuan sebelum diberikan media leaflet dengan sesudah diberikan media leaflet yaitu 10,23 menjadi 14,30 dengan nilai $\mathrm{p}=0,001(\mathrm{p}<0,05)$, maka dapat disimpulkan bahwa ada pengaruh media leaflet terhadap pengetahuan responden tentang kanker serviks. Selanjutnya terjadi perubahan nilai rata-rata pengetahuan sebelum diberikan media pemutaran film dengan sesudah diberikan media pemutaran film yaitu 10,20 menjadi 15,40 dengan nilai $\mathrm{p}=0,001 \quad(\mathrm{p}<0,05)$, maka dapat disimpulkan bahwa ada pengaruh diberikan media pemutaran film terhadap pengetahuan tentang kanker serviks.

Pada kontrol terjadi perubahan nilai rata-rata pengetahuan pada pengukuran I dan pengukuran II yaitu 8,63 menjadi 10,60 dengan nilai $\mathrm{p}<0,085$, maka dapat disimpulkan bahwa tidak ada perbedaan pengetahuan tentang kanker serviks pada pengukuran I dan pengukuran II.Untuk lebih jelas dapat dilihat pada tabel berikut:

Tabel 1. Pengaruh Media Leaflet dan Film terhadap Pengetahuan dengan Kontrol sebagai Pembanding

\begin{tabular}{|c|c|c|c|c|}
\hline \multirow[t]{2}{*}{ Variabel } & \multicolumn{4}{|c|}{ Pengetahuan } \\
\hline & Mean & $\Delta$ & $T$ & $P$ \\
\hline \multicolumn{5}{|l|}{ Leaflet } \\
\hline Sebelum & 10,23 & 4,07 & -9.670 & 0.001 \\
\hline Sesudah & 14,30 & & & \\
\hline \multicolumn{5}{|l|}{ Film } \\
\hline Sebelum & 10,20 & 4,77 & $-18,766$ & 0,001 \\
\hline
\end{tabular}




\begin{tabular}{lllll}
\hline Sesudah & 15,40 & & & \\
Kontrol & & & & \\
Pengukuran I & 8,63 & 1,97 & $-7,971$ & 0,001 \\
Pengukuran II & 10,60 & & & \\
\hline
\end{tabular}

Pemberian pendidikan kesehatan dengan metode leaflet ternyata mampu meningkatkan pengetahuan wanita usia subur yang telah menikah tentang kanker serviks. Hal ini sesuai dengan penelitian Supardi (2002) yang dikutip Sri (2009) bahwa terdapat pengaruh metode pemberian leaflet terhadap peningkatan pengetahuan ibu tentang pengobatan diri sendiri.

Berdasarkan hasil penelitian Nasution (2015), diketahui bahwa media leaflet memang efektif untuk meningkatkan pengetahuan yaitu terdapat peningkatan 1 skor pengetahuan dengan peningkatan rata - rata skor 7.28 setelah diberikan media leaflet. Kenaikan skor ini menunjukkan bahwa ada pengaruh media leaflet pada peningkatan pengetahuan.

Notoatmodjo (2012) menyatakan bahwa dalam pendidikan kesehatan, metode pendidikan yang bersifat individual ini digunakan untuk membina perilaku baru, atau seseorang yang mulai tertarik kepada suatu perubahan perilaku atau inovasi (perubahan sikap untuk mau melakukan pemeriksaan deteksi dini kanker serviks). Penjelasan dibaca dan dilihat dari leaflet yang menarik dapat membawa perubahan, ia tertarik atau mau menerima perubahan, untuk mengetahui apakah perilaku yang sudah atau yang akan diadopsi dari sebuah leaflet itu mempunyai dasar pengertian dan kesadaran yang kuat.

Hal ini sesuai yang dinyatakan Putri (2009) bahwa semua peserta yang diberikan pendidikan kesehatan dengan metode film dapat belajar dari film baik yang pandai maupun yang kurang pandai. Hal dikarenakan karena isi pesan pada film dapat berpengaruh secara signifikan terhadap perasaan, emosi, tingkat penerimaan atau penolakan terhadap informasi yang diberikan (Nurseto, 2011).

Penelitian ini memberikan pendidikan kesehatan dengan pemutaran film, dimana film yang diputar berisikan informasi tentang kanker serviks, dari mulai penyebab, bagian - bagian yang terinfeksi, bentuk - bentuk pencegahan dan proses penyembuhan dari kanker tersebut. Hal inilah yang diasumsikan meningkatkan pengetahuan responden tentang kanker serviks. Notoatmodjo (2012) yang mengutip pendapat Bandura (1968), pengetahuan atau tingkah laku model yang terdapat dalam media audiovisual akan merangsang peserta untuk meniru atau menghambat tingkah laku yang tidak sesuai dengan tingkah laku yang ada di media.

Pemutaran film dapat dilakukan dengan menggunakan media salah satunya dengan alat bantu AVA (Audio Visual Aids). Machfoedz, dkk (2005) menyatakan bahwa AVA merupakan alat - alat pendidikan dalam bidang kesehatan merupakan alat saluran yang dapat digunakan untuk menyampaikan kesehatan karena alat alat tersebut digunakan untuk mempermudah penerimaan pesan - pesan kesehatan bagi masyarakat atau klien.

\section{Pengaruh Pendidikan Kesehatan dengan Metode Leaflet dan Film Terhadap Partisipasi tentang Deteksi Dini Kanker Serviks dengan Kontrol sebagai Pembanding}

Pengaruh media leaflet terhadap partisipasi tentang kanker serviks dan diketahui bahwa terdapat peningkatan rata-rata partisipa si sebelum diberikan media leaflet dengan sesudah diberikan media leaflet yaitu 1,83 menjadi 3,77 dengan nilai $\mathrm{p}=0,001 \quad(\mathrm{p}<0,05)$, maka dapat disimpulkan bahwa ada pengaruh media leaflet terhadap partisipasi responden tentang pemeriksaan kanker serviks. Selanjutnya terdapat peningkatan rata-rata partisipasi sebelum diberikan media pemutaran film dengan sesudah diberikan media pemutaran film yaitu 2,33 menjadi 2,87 dengan nilai $\mathrm{p}=0,001 \quad(\mathrm{p}<0,05)$, maka dapat disimpulkan bahwa ada pengaruh media pemutaran film terhadap partisipasi pemeriksaan kanker serviks.

Pada kontrol diketahui bahwa terdapat peningkatan rata-rata partisipasi pada pengukuran I dan pengukuran II yaitu 1,70 menjadi 2,43 dengan nilai $\mathrm{p}=0,001 \quad(\mathrm{p}<0,05)$, maka dapat disimpulkan bahwa tidak ada perbedaan partisipasi pemeriksaan kanker serviks pada pengukuran I dan pengukuran II.Untuk lebih jelas dapat dilihat pada tabel berikut:

Tabel 2. Pengaruh Media Leaflet dan Film terhadap Partisipasi tentang Deteksi Dini Kanker Serviks dengan Kontrol sebagai pembanding

\begin{tabular}{|c|c|c|c|c|}
\hline \multirow[t]{2}{*}{ Variabel } & \multicolumn{4}{|c|}{ Partisipasi } \\
\hline & Mean & $\Delta$ & $\mathrm{Z}$ & $P$ \\
\hline \multicolumn{5}{|l|}{ Leaflet } \\
\hline Sebelum & 1,83 & 1,93 & \multicolumn{2}{|c|}{$-4,8500.001$} \\
\hline Sesudah & 3,77 & & & \\
\hline \multicolumn{5}{|l|}{ Film } \\
\hline Sebelum & 1,80 & 1,73 & 4,850 & 0.001 \\
\hline Sesudah & 3,70 & & & \\
\hline \multicolumn{5}{|l|}{ Kontrol } \\
\hline Pengukuran I & 1,70 & 0,73 & 4,300 & 0.001 \\
\hline Pengukuran II & 2,43 & & & \\
\hline
\end{tabular}

Berdasarkan hasil penelitian Saraswati (2011), disimpulkan bahwa ada perbedaan partisipasi sebelum dan sesudah penyuluhan dengan leaflet, terdapat peningkatan partisipasi setelah diberikan penyuluhan dengan metode leaflet.

Berdasarkan hasil penelitian Saraswati (2011), diketahui bahwa ada perbedaan partisipasi sebelum dan sesudah penyuluhan dengan media film. Mean rank media film diperoleh negative rank $=0,00$ dan positive rank $=$ 14,50 untuk rangking positif lebih besar dibandingkan rangking negative menunjukkan bahwa perbedaan bernilai positif. Dengan kata lain penyuluhan dengan media film menyebabkan peningkatan partisipasi.

Rendahnya partisipasi responden untuk ikut serta pada pemeriksaan kanker serviks juga dapat dilihat dari hasil jawaban responden pada item pertanyaan partisipasi. 
Pada pertanyaan no 5 yaitu apakah anda memiliki ketertarikan untuk melakukan pap smear, paling banyak responden menjawab tidak pada pertanyaan tersebut, serta waktu ditanya Apakah anda sudah pernah mengajak teman untuk ikut serta banyak juga responden menjawab tidak. Namun, walaupun setelah dilakukan pendidikan kesehatan baik itu dengan leaflet maupun film sudah terjadi perubahan pada jawaban responden, tetap saja tidak banyak meningkatkan partisipasi responden untuk ikut serta pada pemeriksaan kanker serviks. Hal tersebut karena masih banyaknya responden yang mengatakan malu dan takut untuk melakukan pemeriksaan pap smear karena mereka melihat langsung pada film bagaimana cara pemeriksaan pap smear.

Hal ini sesuai dengan temuan dilapangan, bahwa Dinas Kesehatan Padangsidempuan Selatan tidak memberikan pendidikan kesehatan tentang program deteksi dini kanker serviks dengan metode pap smear. Setelah diberikan pendidikan kesehatan, maka dapat dilihat bahwa pengetahuan dan partisipasi masyarakat kampung darek kecamatan padangsidempuan selatan meningkat terhadap deteksi dini kanker serviks.

Perbedaan Pengaruh Media Leaflet, Media Film dan Kontrol terhadap Pengetahuan Responden tentang Kanker Serviks

Hasil penelitian diketahui terdapat perbedaan perubahan partisipasi pemeriksaan kanker serviks antara ketiga kelompok, yaitu kelompok media leaflet,media film dan kontrol $(\mathrm{p}=0,001)$. Mean Rank partisipasi yang paling tinggi adalah pada kelompok media leaflet. Untuk lebih jelas dapat dilihat pada tabel berikut :

Tabel 3. Perbedaan Pengaruh Media Leaflet, Film dan Kontrol terhadap Perubahan Partisipasi

\begin{tabular}{lll}
\hline Media & Mean Rank & $\boldsymbol{P}$ \\
\hline Leaflet & 57,43 & 0,001 \\
Film & 53,10 & \\
Kontrol & 25,97 & \\
\hline
\end{tabular}

\section{KESIMPULAN}

1. Pemberian pendidikan kesehatan dengan metode leaflet meningkatkan pengetahuan tentang kanker serviks pada WUS di Lingkungan Kampung Darek Kecamatan Padangsidempuan Selatan Kota Padangsidempuan.

2. Pemberian pendidikan kesehatan dengan pemutaran film meningkatkan pengetahuan tentang kanker serviks pada WUS di Lingkungan Kampung Darek Kecamatan Padangsidempuan Selatan Kota Padangsidempuan.

3. Pemberian pendidikan kesehatan dengan metode leaflet meningkatkan partisipasi keikutsertaan pap smear pada WUS di Lingkungan Kampung Darek Kecamatan Padangsidempuan Selatan Kota Padangsidempuan.
4. Pemberian promosi kesehatan dengan pemutaran film meningkatkan partisipasi keikutsertaan pap smear pada WUS di Lingkungan Kampung Darek Kecamatan Padangsidempuan Selatan Kota Padangsidempuan.

5. Nilai rata - rata pengetahuan yang paling tinggi adalah pada kelompok media film.

6. Nilai rata - rata partisipasi yang paling tinggi adalah pada kelompok media leaflet.

\section{SARAN}

1. Dinas Kesehatan Kota Padangsidempuan Selatan agar memberikan pendidikan kesehatan tentang program deteksi dini kanker serviks seperti pap smear pada seluruh wanita dengan media leaflet dan media film untuk mencegah dan menangani segera kanker serviks, dan menyediakan tenaga kesehatan wanita, karena WUS malu untuk pap smear jika dilakukan oleh tenaga kesehatan pria.

2. Bagi tenaga kesehatan yang ada di Lingkungan Kampung Darek Kecamatan Padangsidimpuan Kota Padangsidimpuan agar membuat media pendidikan kesehatan yang lebih menarik baik berupa leaflet maupun media film tentang kanker serviks agar lebih menarik minat masyarakat dalam menambah pengetahuan dan partisipasi dalam mendeteksi kanker serviks, dan media yang ditampilkan harus memuat semua informasi yang dibutuhkan oleh WUS sehingga meningkat partisipasi mereka untuk ikut pap smear

3. Bagi karang taruna, posyandu dan kader-kader kesehatan yang ada di Lingkungan Kampung Darek Kecamatan Padangsidimpuan selatan untuk ikut serta menggerakkan ibu-ibu agar mau melalukan deteksi dini kanker serviks

\section{DAFTAR PUSTAKA}

Dewi, S., M., N., Suryani, N., Murdani, P., 2013, Hubungan Pengetahuan dengan Sikap WUS dengan pemeriksaan IVA di Puskesmas Buleleng Surabaya, Jurnal Magister Kedokteran Keluarga 1 (1), 57-66.

Direktorat Jenderal Pengendalian Penyakit dan Penyehatan Lingkungan Departemen Kesehatan RI, 2013, Profil Kesehatan Indonesia Tahun 2013: Jakarta.

Machfoedz, dkk, 2005, Metodologi Penelitian Bidang Kesehatan, Keperawatan dan kebidanan, Yogyakarta: Fitrimaya.

Nasution, D., Y., 2015, Efektivitas KIE (Komunikasi,Informasi Dan Edukasi) Metode Ceramah dan Pemutaran Film Terhadap Pengetahuan dan Sikap Ibu Hamil Tentang Zat Besi Di Kecamatan Padangsidimpuan Tenggara Tahun 2014, Universitas Sumatera Utara Medan. Program Studi S2 Ilmu Kesehatan Masyarakat Fakultas Kesehatan Masyarakat 
Notoatmodjo, S., 2012, Promosi Kesehatan dan Ilmu Prilaku, Jakarta ; Penerbit Rineka Cipta.

Nurseto.2011. Membuat Media Pembelajaran yang Menarik. Jurnal Ekonomi dan Pendidikaan, 8(1):19-34.

Ocvyanti, 2013, Peran Dokter Umum dalam Pencagahan Kanker Serviks di Indonesia Journal Indonesia Med Assoc,63(1),1-3

Putri, P.K.D. 2009. Pengaruh Tingkat Pendidikan, Pengetahuan, Sikap dan Terpaan Iklan Layanan Masyarakat KB Versi Shireen Sungkar dan Teuku Wisnu di TV terhadap Perilaku KB pada Wanita atau Pria dalam Usia Subur. Jurnal Interaksi, 1(1):1-11.

Rachmadahniar, 2005, Dukungan Suami terhadap Partisipasi Wanita dalam Program Skrining Kanker Leher Rahim di Biro Konsultasi Kanker Yayasan
Kucula Yogyakarta, Tesis, Fakultas Kesehatan Masyarakat : Universitas Gadjah Mada.

Saraswati, L.K., 2011, Pengaruh Promosi Kesehatan Terhadap Pengetahuan Tentang Kanker Serviks dan Partisipasi Wanita Dalam Deteksi Dini Kanker Serviks, Tesis, Universitas Sebelas Maret.

Setiati, E., 2009, Waspadai 4 Kanker Ganas Pembunuh Wanita, Andi, Yogyakarta.

Sugiar, R.H., 2013, Efektivitas penggunaan Metode Analisis Teks Teknik Catatan Tulis dan Susun (TS) pada Pembelajaran Shokyu Choukai II, Tesis, Universitas Pendidikan Indonesia.

Tyastuti, dkk., 2008, Komunikasi \& Konseling Dalam Praktek Kebidanan, Yogyakarta. 